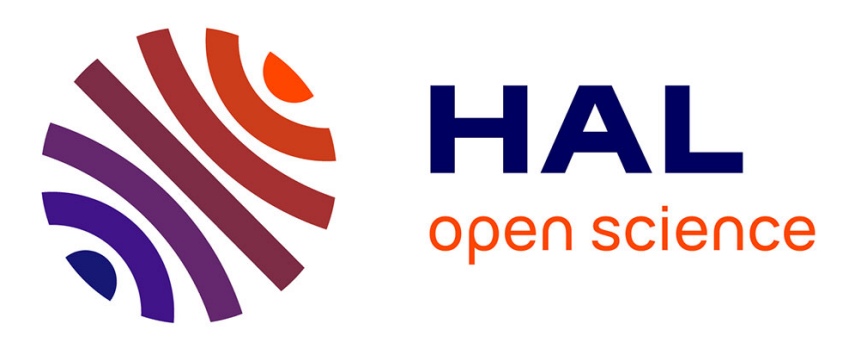

\title{
Status of the PHOENIX ECR charge breeder at ISOLDE, CERN
}

C. Barton, J. Cederkall, P. Delahaye, O. Kester, T. Lamy, M. Marie-Jeanne

\section{To cite this version:}

C. Barton, J. Cederkall, P. Delahaye, O. Kester, T. Lamy, et al.. Status of the PHOENIX ECR charge breeder at ISOLDE, CERN. 12th International Conference on Ion Sources (ICIS'07), 2007, Jeju, South Korea. pp.02A905, 10.1063/1.2819746 . in2p3-00168586

\section{HAL Id: in2p3-00168586 https://hal.in2p3.fr/in2p3-00168586}

Submitted on 29 Aug 2007

HAL is a multi-disciplinary open access archive for the deposit and dissemination of scientific research documents, whether they are published or not. The documents may come from teaching and research institutions in France or abroad, or from public or private research centers.
L'archive ouverte pluridisciplinaire $\mathbf{H A L}$, est destinée au dépôt et à la diffusion de documents scientifiques de niveau recherche, publiés ou non, émanant des établissements d'enseignement et de recherche français ou étrangers, des laboratoires publics ou privés. 


\title{
Status of the PHOENIX ECR charge breeder at ISOLDE, CERN*
}

\author{
Charles Barton, ${ }^{1}$ Joakim Cederkall, ${ }^{2}$ Pierre Delahaye, ${ }^{2}$ Oliver \\ Kester, ${ }^{3}$ Thierry Lamy, ${ }^{2,4}$ and Mélanie Marie-Jeanne ${ }^{2,4}$ \\ (IS397 Collaboration) \\ ${ }^{1}$ University of York, Heslington, York, United Kingdom \\ ${ }^{2}$ CERN, Physics Department-ISOLDE, Geneva, Switzerland \\ ${ }^{3}$ GSI, Darmstadt, Germany \\ ${ }^{4}$ LPSC, Grenoble, France
}

(Dated: August 26, 2007)

\begin{abstract}
We report here on the last progresses made with the PHOENIX ECR charge breeder test bench at ISOLDE. Recently, an experiment was performed to test the trapping of ${ }^{61} \mathrm{Fe}$ daughter nuclides from the decay of ${ }^{61} \mathrm{Mn}$ nuclides. Preliminary results are given.
\end{abstract}

PACS numbers: 29.25.Ni, 07.77.Ka, 52.50.Sw

Keywords: ion sources, ion trap, charge breeding

* Contributed paper, published as part of the Proceedings of the 12th International Conference on Ion Sources, Jeju, Korea, August 2007. 


\section{INTRODUCTION}

In the perspective of future applications of charge bred beams to nuclear physics or solid states physics experiments, a PHOENIX ECR Booster is undergoing performance tests at ISOLDE. A first part of the investigation of the on-line performances of the ECR charge breeder was presented at ICIS05 [1], showing preliminary results of the afterglow method with stable beam. As a second step, beam times planned for this year concentrate on three topics: the study of the dependence of the charge breeding process on the chemical properties of the injected ion beam, the possibility of trapping and charge breeding daughter nuclides in the plasma, and the tests of the afterglow method with radioactive ion beams.

\section{A. Status of the PHOENIX ECR Booster test bench}

The PHOENIX ECR Booster is installed as a test bench on the Heavy Masses beamline after the General Purpose Separator (GHM) at ISOLDE [2], as shown on Fig. 1. Singly charged ions produced by ISOLDE are injected into the charge breeder where they are stepwise ionized by collisions with energetic electrons of the ECR plasma [3]. After extraction, the charge states are separated by a $102^{\circ}$ magnetic dipole and directed towards either a faraday cup, or a tape station set up after the faraday cup at the end of the beamline. Various technical developments have been undertaken, which were described in previous references $[4]$.

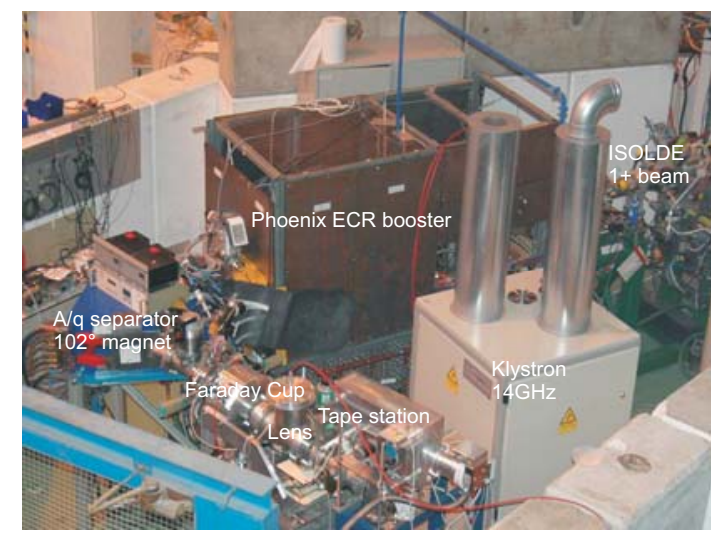

FIG. 1: Layout of the PHOENIX ECR Booster test bench in ISOLDE hall 


\section{B. Program of investigation}

The current program for tests $[5,6]$ is mainly dedicated to the study of the performances of the ECR charge breeder in view of its future use at RIB facilities, i.e. as the first part of a postaccelerator, or as a stand-alone device for preparing beam for nuclear physics experiments. Several applications of the latter type have already been imagined, leading to experiments [7], and more recently to the proposal of new experiments [8-10]. In these cases, the ECR charge breeder is used as a purifying device, either by using the charge state distribution for ions of different $\mathrm{Z}$ values, or the injection and breaking up of molecular sidebands from the ISOLDE target and ion source. At last, a test of the trapping of the daughter nuclides has been recently performed, which could open possibilities for the production and study of new radioactive ion beams.

\section{CHARGE BREEDING OF DAUGHTER NUCLIDES}

In some specific cases, beams of isotopes that are not directly accessible with the ISOL production method can be produced from the beta decay of their mother nuclide. One possible method is the trapping of the mother nuclides for several half-lives. Such a technique was used by the ISOLTRAP experiment to measure the mass of neutron-rich iron isotopes $[11,12]$ that are not directly produced at the ISOLDE facility [13].

In order to estimate the efficiency for trapping and charge breeding a daughter nuclide within the ECR plasma, a similar experiment was performed with the PHOENIX Booster.

\section{A. Experimental setup}

${ }^{61} \mathrm{Mn}$ isotopes were produced by the bombardment of an UCx target by pulses of $10^{13}$ protons delivered from the PS booster at an energy of $1.4 \mathrm{GeV}$, and ionized by resonant laser ionization. They were injected during a fixed time into the PHOENIX Booster, where the axial magnetic field was configured in trapping mode. The time between the end of the injection and the afterglow pulse, that is refered in the following as trapping time, could be varied from one measurement cycle to another around the half-life of ${ }^{61} \mathrm{Mn}$, i.e. 670 (40)ms [14]. The measurements were repeated over cycles of $30 \mathrm{~min} .{ }^{61} \mathrm{Mn}$ decays to ${ }^{61} \mathrm{Fe}$ which has a half-life of $5.98(0.06) \mathrm{min}$ [14]. After the trapping time, charge bred ${ }^{61} \mathrm{Mn}$ ions are 
released, and possibly some charge bred ${ }^{61} \mathrm{Fe}$ ions as well, as an afterglow pulse. After charge state separation, they are implanted on a tape shown on Fig. 2 for beta-gamma coincidence measurement.

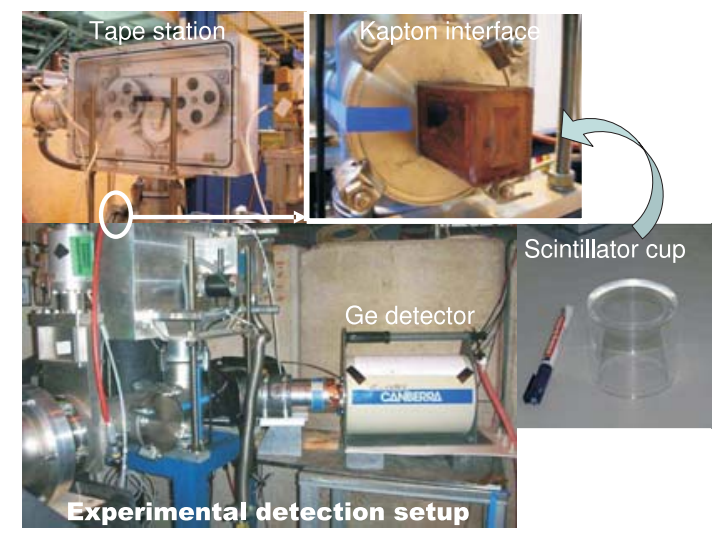

FIG. 2: Detection setup at the end of the PHOENIX Booster beamline. A NE102 scintillator cup surrounds the implantation point for beta counting, and a Germanium detector positioned close to the scintillator provides gamma identification.

As shown in Fig. 3, each measurement starts with one proton pulse and ends with the tape motion for the removal of most of the remaining activity. The analyzing magnet was set to select mass 61 with a $12+$ charge state.

\section{B. Preliminary results}

The beta-gamma events were recorded using a Time-to-Amplitude-Converter (TAC) showing the time structure of the coincidences. As shown on Fig. 4, the proportion of events recorded as "gamma-gamma coincidences" is quite high as compared to the beta-gamma coincidence events. Such an effect might come from the thickness of the scintillator that provides a double counting of the gammas, as well as from the high X-ray background.

Once gating on the beta-gamma coincidences, the gamma spectrum as given in Fig. 5 allows identification of the ${ }^{61} \mathrm{Mn}$ and ${ }^{61} \mathrm{Fe}$ main lines. By gating on these respective gamma lines, the decay curves of ${ }^{61} \mathrm{Mn}$ and ${ }^{61} \mathrm{Fe}$ were plot, as shown on Fig. 3. At this stage, more analysis is required for suppressing the background coming from deposition of part of the charge bred beam around the tape, and for determining the respective parts of the ${ }^{61} \mathrm{Fe}$ 


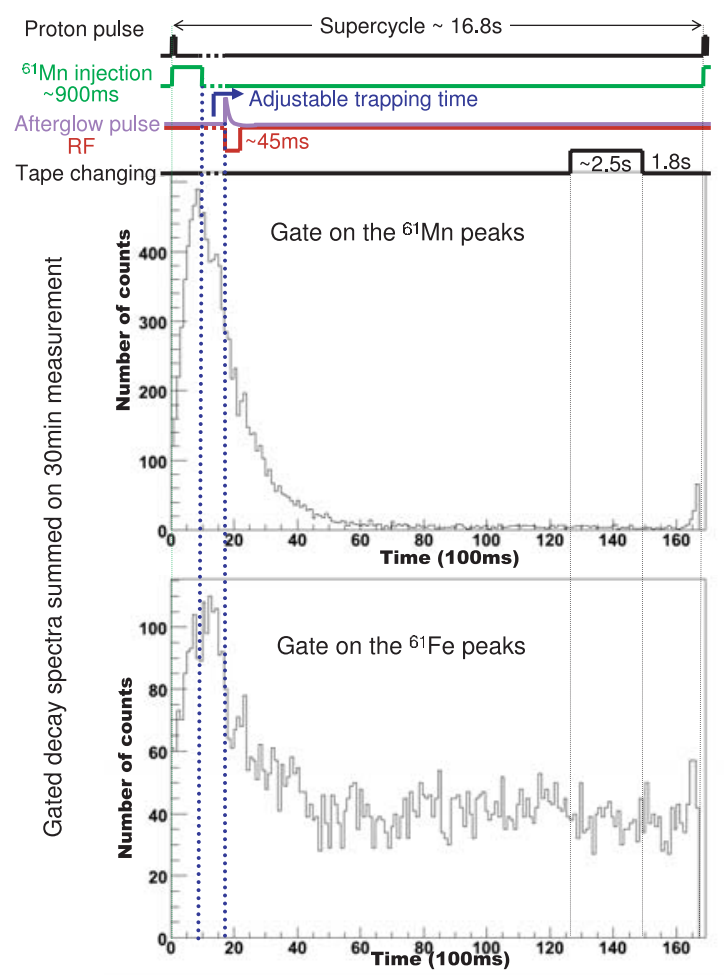

FIG. 3: Decay curves of ${ }^{61} \mathrm{Mn}$ and ${ }^{61} \mathrm{Fe}$ for a measurement cycle of $30 \mathrm{~min}$ with $800 \mathrm{~ms}$ trapping. The timing of the measurements is given on the diagram above.

gamma lines coming from the implantation onto the tape of ${ }^{61} \mathrm{Mn}^{12+}$ or ${ }^{61} \mathrm{Fe}^{12+}$. For similar reasons, the expected increase of the activity after the afterglow pulse is also not visible on these spectra. As it was observed for the charge states of stable ${ }^{16} \mathrm{O}$, the afterglow pulse sits on the top of a small DC level that was difficult to suppress completely during the time of the experiment. Finally the exponential decay law followed by the two isotopes smears and spreads out the time structure of the pulse.

For background suppression, other types of cycles were realized with the beam gate off (no injection of ${ }^{61} \mathrm{Mn}^{+}$), and the faraday cup blocking or not the way of the charge bred beam to the tape station. Fig. 6 shows an example of a sequence of cycles for no trapping time. Remarkable enough, the soudain drop of the average activity for the ${ }^{61} \mathrm{Fe}$ beta-gamma coincidences between the last two cycles (beam gate off for both, faraday cup out for the first one and in for the last one) indicates that there was still some ${ }^{61} \mathrm{Fe}^{12+}$ coming from the ECR plasma for long times after the injection of ${ }^{61} \mathrm{Mn}$ was stopped. Obviously a part of the 


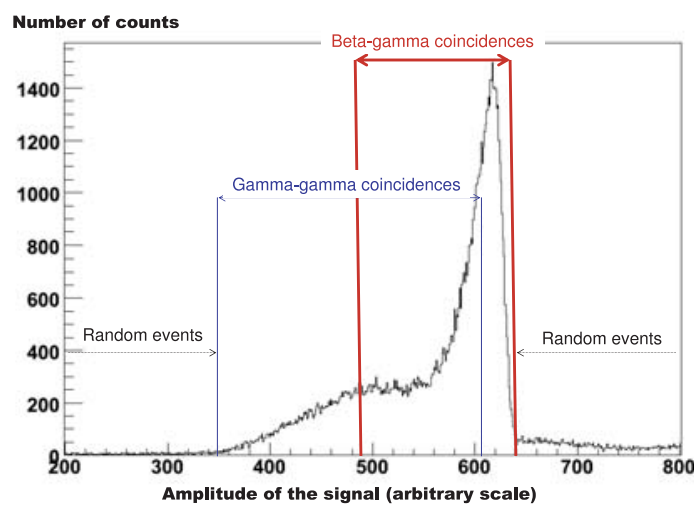

FIG. 4: Zoom on the coincidence events of the Time Amplitude Converter (TAC) spectrum for a measurement with $800 \mathrm{~ms}$ trapping time.

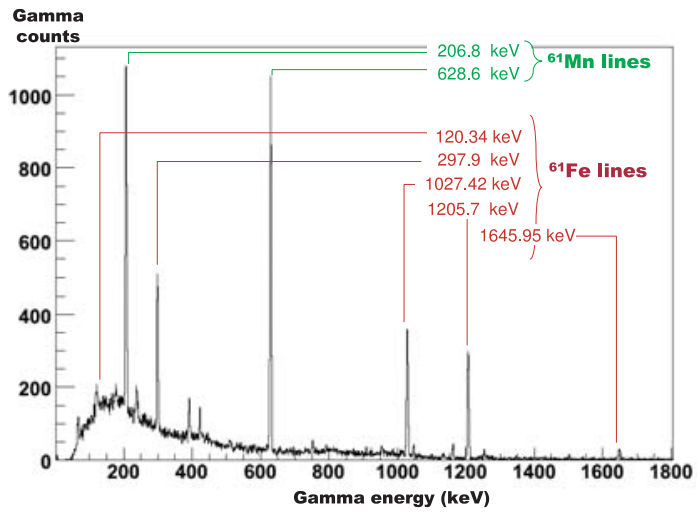

FIG. 5: Gamma spectrum gated on the coincidence events for a 30 min measurement cycle with 800ms trapping.

${ }^{61} \mathrm{Fe}$ isotopes could be kept or recycled in the plasma over times probably larger than 1 min.

\section{OUTLOOK}

The mechanism of trapping or recycling of ${ }^{61} \mathrm{Fe}$ daughter nuclides from the decay of ${ }^{61} \mathrm{Mn}$ observed in this experiment will be further investigated by a more detailed analysis. A careful suppression or treatment of the background should permit to obtain more information about 


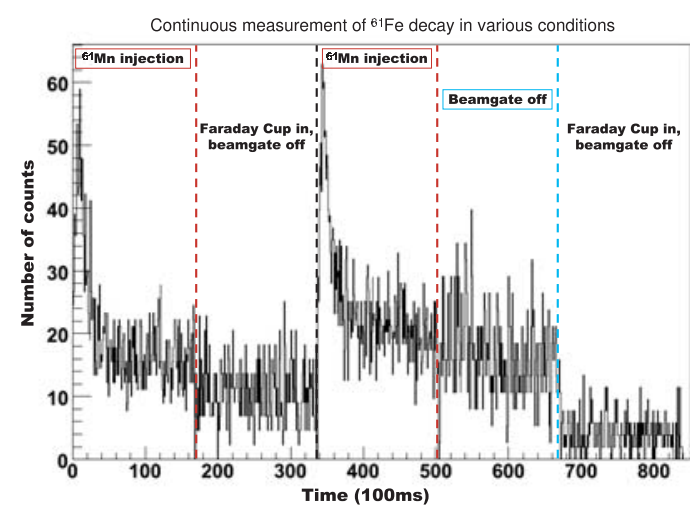

FIG. 6: Decay curve of ${ }^{61} \mathrm{Fe}$ for successive cycles (normalized on 30min each) and no trapping time. The count rate drops significantly in the last section with the insertion of the Faraday Cup: this shows that ${ }^{61} \mathrm{Fe}$ isotopes were still released from the plasma while the beamgate was off in the previous cycle.

its nature and quantitative results concerning its efficiency.

[1] P. Delahaye, C. J. Barton, K. Connell, T. Fritioff, O. Kester, T. Lamy, M. Lindroos, P. Sortais, G. Transtrmer, F. Wenander, Rev. Sci. Instrum. 77 (2006) 03 B105.

[2] E. Kugler, Hyp. Int. 129 (2000) 23.

[3] R. Geller, Electron cyclotron resonance ion sources and ECR plasmas, Bristol: IOP (1996) $\mathrm{p} 434$.

[4] M. Marie-Jeanne, P. Delahaye, High Energy Physics and Nuclear Physics 31-S1 (2007) 216218.

[5] CERN/INTC 2001-023 / INTC/P-143 (2001)

[6] CERN/INTC 2005-022 / INTC/P-143-ADD-1 (2005)

[7] T. Fritioff et al., Nucl. Inst. Meth. A (2006) 31-37.

[8] CERN-INTC-2007-012 / INTC-P-225 (2007)

[9] M. Marie-Jeanne, P. Delahaye, POS(NIC-IX-087) (2006).

[10] M. Marie-Jeanne, P. Delahaye, EMIS2007 conference proceedings, in preparation.

[11] A. Herlert et al., GSI Scientific Report 2006 / GSI Report 2007-1, (2007) 255.

[12] A. Herlert et al., in preparation. 
[13] ISOLDE yields, http : //isolde.web.cern.ch/ISOLDE/, http : //oraweb.cern.ch : 9000/pls/isolde/querytgt.

[14] G. Audi et al., Nucl. Phys. A 729 (2003) 3-128. 


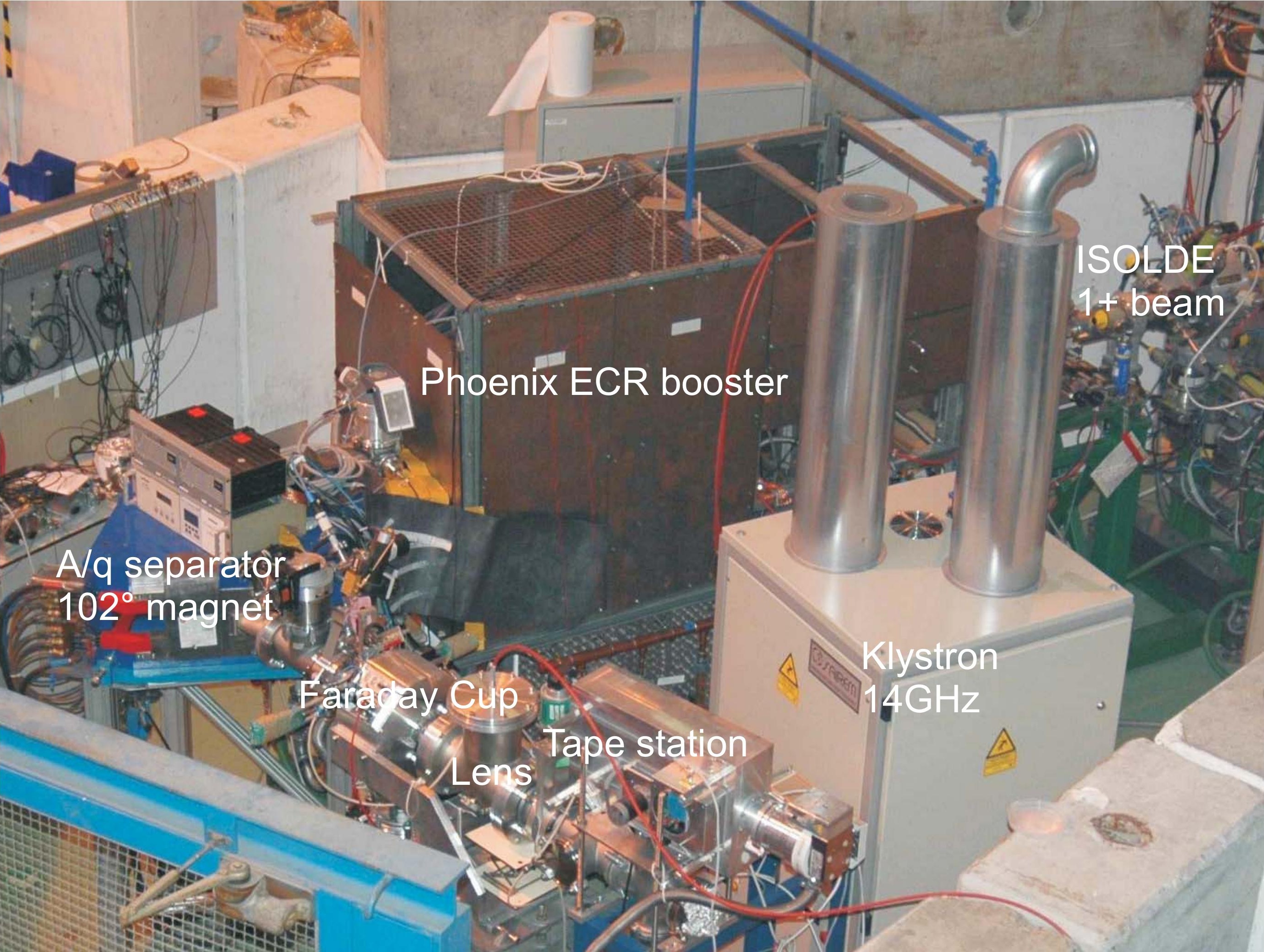




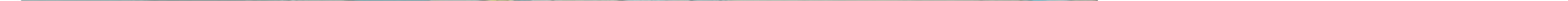


Proton pulse

Supercycle $\sim 16.8 \mathrm{~s}$

${ }^{61} \mathrm{Mn}$ injection

$\sim 900 \mathrm{~ms}$

Afterglow pulse RF

Tape changing

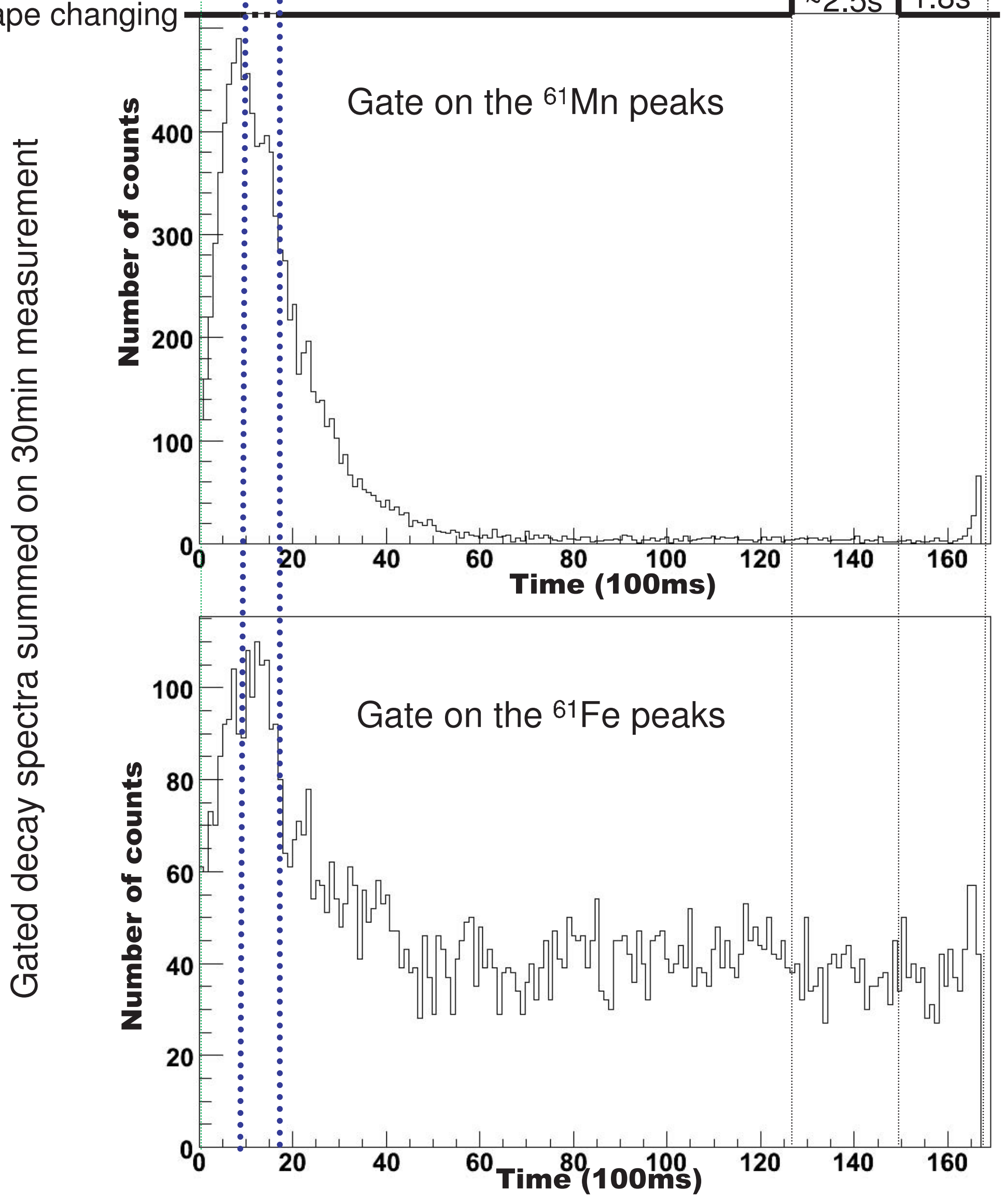




\section{Number of counts}

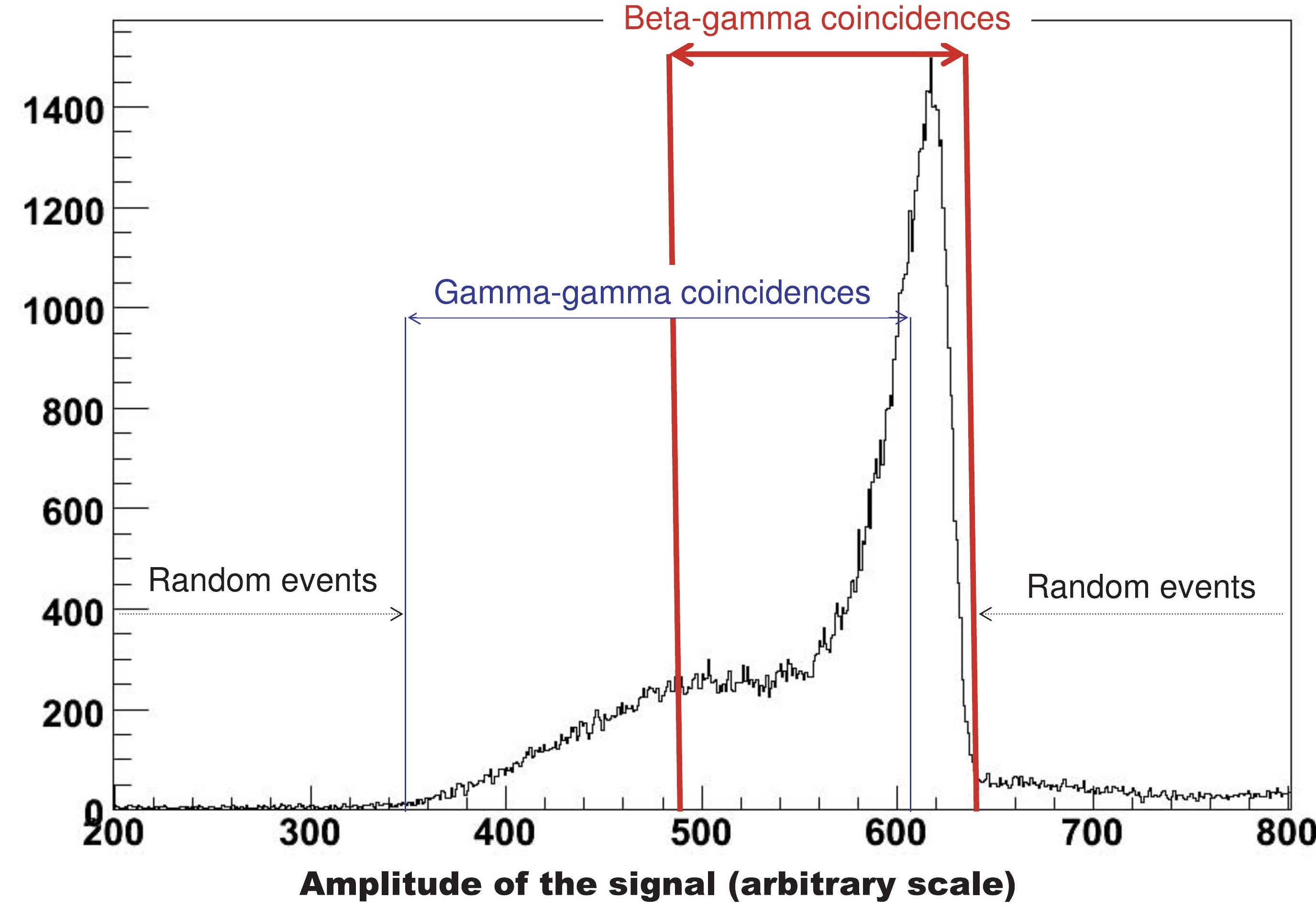


Continuous measurement of ${ }^{61} \mathrm{Fe}$ decay in various conditions

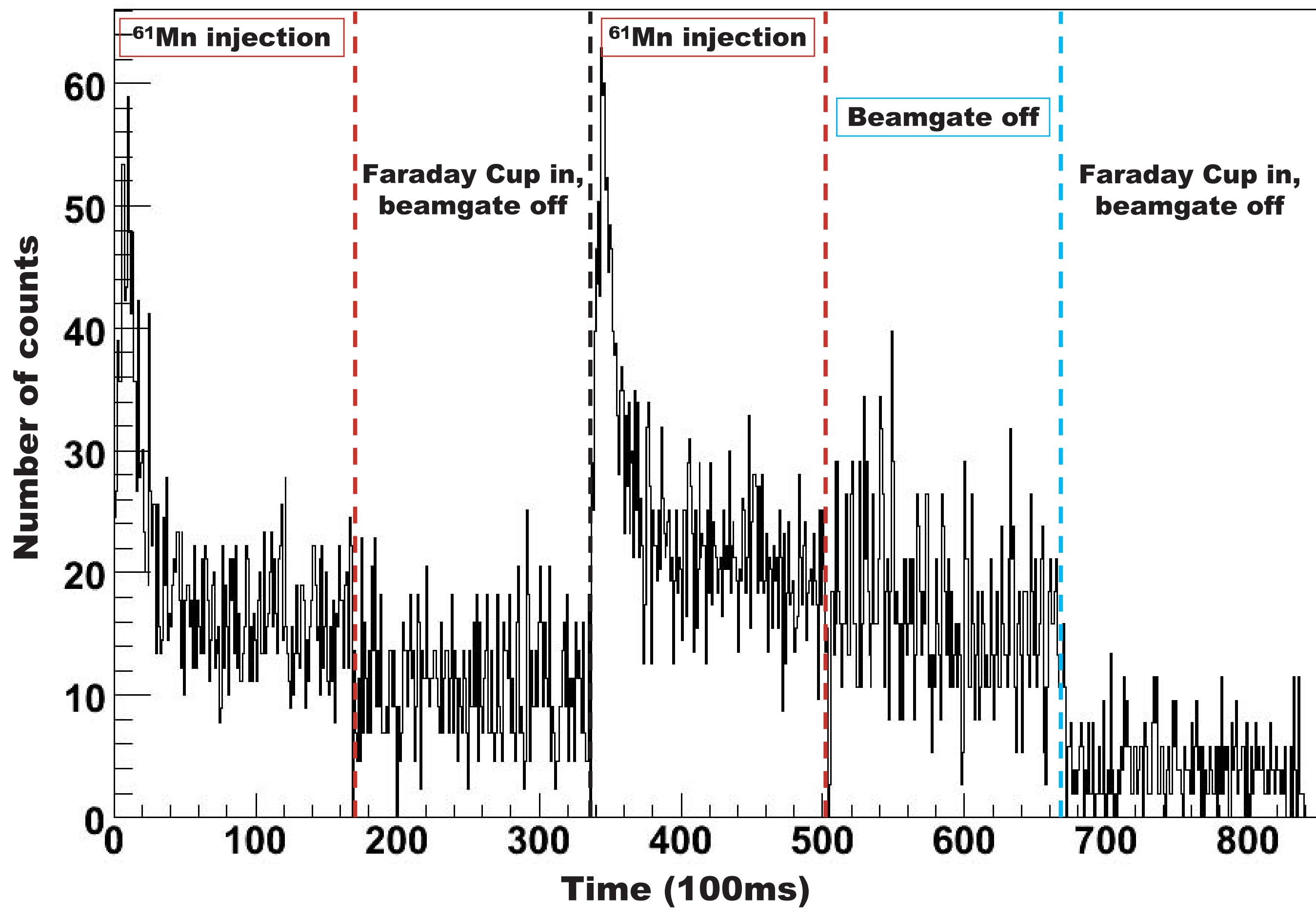

